\title{
DESIGNING HOSPITAL ANTITRUST \\ POLICY TO PROMOTE SOCIAL WELFARE
}

\author{
Daniel Kessler \\ Mark McClellan
}

Working Paper 6897

http://www.nber.org/papers/w6897

\author{
NATIONAL BUREAU OF ECONOMIC RESEARCH \\ 1050 Massachusetts Avenue \\ Cambridge, MA 02138 \\ January 1999
}

We would like to thank David Becker, Kristin Madison, and Abigail Tay for exceptional research assistance. Also, we would like to thank Richard Hamer and InterStudy for providing information on HMO enrollment. Funding from the National Science Foundation and the National Institutes on Aging through the NBER is gratefully appreciated. All errors are our own. The views expressed here are those of the author and do not reflect those of the National Bureau of Economic Research or the U.S. Treasury.

(C) 1999 by Daniel Kessler and Mark McClellan. All rights reserved. Short sections of text, not to exceed two paragraphs, may be quoted without explicit permission provided that full credit, including ${ }^{\circ}$ notice, is given to the source. 
Designing Hospital Antitrust Policy to Promote Social Welfare

Daniel Kessler and Mark McClellan

NBER Working Paper No. 6897

January 1999

\section{ABSTRACT}

Applying principles of merger evaluation to the health care industry in general, and to hospital markets in particular, poses several unique challenges. Definition of relevant geographic markets and assessment of the consequences of changes in competition for patient and social welfare are complicated by asymmetric information and moral hazard due to health insurance. We suggest a new empirical approach to assessing the impact of hospital competition which addresses the shortcomings of existing methods. We then summarize our main results on the welfare consequences of competition. We conclude with an illustration of how our methods can be used to assess the welfare implications of specific hospital mergers, and with some implications of our findings for antitrust policy.

Daniel Kessler

Graduate School of Business

Stanford University

Stanford, CA 93405-5015

and NBER

fkessler@pound.stanford.edu
Mark McClellan

Department of the Treasury

1500 Pennsylvania Avenue, NW

Washington, DC 20220 


\section{Introduction}

Government policies toward competition among health care providers have been the subject of considerable debate (Gaynor and Vogt 1998). In the health care industry, competition policy most often focuses on hospital mergers, though mergers among physician organizations and insurers are increasingly facing antitrust scrutiny.

The general process of merger evaluation is well-developed. First, the relevant market is defined, in terms of both products and geography. The geographic market definition suggested by the U.S. Department of Justice/Federal Trade Commission Merger Guidelines (1992) for assessing the impact of competition on social welfare (Vistnes 1995; Scheffman and Spiller 1987 ) is that a geographic market should be comprised of the smallest geographic area over which a hypothetical monopolist could profitably impose a small but significant and nontransitory increase in prices. Second, the likely consequences of any changes in competition as a result of the proposed merger are assessed. According to the Merger Guidelines, this part of the evaluation process typically involves identifying the competing firms, and summarizing the likely changes in the extent of competition in terms of a quantitative index. The most widelyused index is the Herfindahl-Hirschman Index (HHI), defined as the sum of squared output shares of the firms in the market. The impact of the proposed merger on welfare is viewed as a function of the change in HHI that would occur as a result of the merger, as well as a function of other factors (such as efficiency gains or the avoidance of closure) that might mitigate or enhance the impact of changes in market structure. All else constant, mergers that result in large increases in the HHI are considered to be more socially harmful than are mergers that do not.

Applying these general principles of merger evaluation to the health care industry poses 
several unique challenges. How should relevant product and geographic markets be defined, when many difficult-to-measure factors like quality of care, asymmetric information, and special payment arrangements may influence the extent to which providers compete with one another? How should the welfare effects of mergers be assessed, when the consequences of the medical production process -- resource use and patient health outcomes - are not only affected by competition, but also by a complex combination of the medical services supplied by providers, insurance arrangements, and unobservable differences in patients' health status? Because of the complexity of health care production and many distinctive features of health care markets, these questions are difficult to answer definitively, on both theoretical and empirical grounds.

We begin by reviewing previous studies on the two key components of evaluations of hospital mergers: the definition of relevant markets, and the assessment of the consequences of changes in competition for patient and social welfare. We then summarize our approach to assessing the impact of hospital competition, the reasons why our approach addresses the shortcomings of existing methods, and oür main results on the welfare consequences of competition (detailed discussion of our methods and results can be found in Kessler and McClellan 1998). We conclude with an illustration of how our methods can be used to assess the welfare consequences of specific hospital mergers, and with some implications of our methods for antitrust policy. 


\section{Previous Studies to Guide Hospital Antitrust Policy}

\section{Market Definition}

In most hospital antitrust cases, market definitions involve evidence on patterns of patients' hospital choices -- the flows of patients to hospitals. Under the Elzinga-Hogarty (1973) method, for example, a market's boundaries are defined so that relatively few consumers purchase services from outside the area, and few outside consumers purchase within the area. Much of the debate in antitrust cases centers on what constitutes "significant" patient flows, since such flows define the extent of the market. Are outlying suburbs and their community hospitals to be included in the market facing medical centers in a central city? What about the home areas of patients who travel substantial distances for referral care at a well-known teaching hospital?

For all the time that such questions consume in antitrust proceedings, much of the recent economic literature on competition suggests that market definitions based on patient flows may result in a fundamentally misleading picture of competition. Economists regard actual flows as endogenous. For example, suppose that a hospital delivers care of particularly high quality or low cost, not because of competitive pressures from other hospitals but because that hospital has developed good management techniques or contracted with highly-skilled staff. It is likely that patients would be willing to come from farther away to receive this care. According to patient flows, the relevant market containing this hospital would appear to be larger compared to that of an otherwise similar but "average" hospital. Conversely, a community hospital may attract patients only from the very nearest neighborhoods, and thus appear to have a very small market area, not because of any lack of competition but simply because it is a bad hospital. Patient flows 
reflect important factors other than competition among providers, and so they may lead to biased conclusions about the competitiveness of the "market" defined based on these flows. In effect, the method leads to excessive concern over mergers involving low-quality hospitals and insufficient concern over mergers involving high-quality ones.

For example, the "variable radius" method of hospital market definition (e.g., Zwanziger and Melnick 1988) defines the radius of each hospital's relevant geographic market to be equal to the minimum necessary to include a fixed percentage of that hospital's patients, often 60 or 75 percent (Garnick et al. 1987). ${ }^{1}$ However, if variations in hospital quality are difficult for regulators to observe but affect patient choices, estimates of the impact of competition on treatment, expenditures, and health outcomes based on variable-radius geographic markets may be biased (Werden 1989). Moreover, the net effect of the bias is unclear. If unobservably highquality hospitals have higher costs and attract patients from a wider geographic area than do lowquality hospitals, the high-quality hospitals will appear to have larger variable-radius geographic markets, thus appearing to be subject to greater competitive forces. ${ }^{2}$ If the true effect of competition is to reduce costs and improve quality, then unobserved hospital heterogeneity will lead to underestimation of the effect of competition on cost and overestimation of the effect of competition on quality (by leading to the overstatement of the competitive forces facing highcost, high-quality hospitals). If the true effect of competition is to increase costs and worsen

'This method of delineating relevant geographic markets as the smallest area containing suppliers of a fixed fraction of shipments was originally set out by Elzinga and Hogarty (1973, 1978).

${ }^{2}$ Indeed, Phibbs and Robinson (1993) show that academic medical-center status, an accepted structural measure of hospital quality (e.g., Luft et al. 1990), is positively correlated with variable-radius market size. 
outcomes, then unobserved hospital heterogeneity will lead to overestimation of the effect of competition on cost and underestimation of the effect of competition on quality. ${ }^{3}$

The most common method used in research studies to avoid this problem defines a hospital's geographic market as a fixed circular area around its location. The "fixed radius" method of measuring geographic markets defines a hospital's competitors to include all other hospitals located within a fixed distance around the hospital (e.g., Robinson and Luft 1985). ${ }^{4}$ But this method does not solve the market definition problem: it is very unlikely that all hospitals face similar-sized geographic markets, so that the method results in geographic markets that are measured with error. The fixed distance will overstate the true size of some markets and understate the true size of others. For example, consider a fixed-radius definition of hospital market areas that, on average, is equal to the true size of hospital markets. Those markets in which the fixed size overstates the true size of the geographic market will have measures of market structure that overstate the market's competitiveness; those markets in which the fixed size understates the true size will have measures of market structure that understate the market's competitiveness. ${ }^{5}$ To provide a useful guide to market competitiveness, a market definition must

${ }^{3}$ Related problems with the variable-radius method lead to other biases in market defnition. For example, if the variable-radius method tends to measure true geographic market size with error, then effects of competition based on variable-radius markets will be biased toward zero.

${ }^{4} \mathrm{~A}$ variant on this method defines the relevant geographic market to consist of a metropolitan statistical area (e.g., Dranove, Shanley, and White 1993), regardless of actual patient flows within and beyond the MSA.

${ }^{5}$ The bias from such measurement error may be even greater if, as is likely, the measurement error is positively correlated with the competitiveness of the market. If the true size of a hospital market is smaller than average in more-competitive areas (e.g., areas with relatively large numbers of hospitals), then fixed-radius geographic markets will overstate the 
at least consider the types of hospitals in the market and the types of medical services provided or potentially provided by all of these hospitals. A policy based on a fixed market size is not a practical approach to such an evaluation, or an appealing one on common-sense grounds, because it does not reflect many factors that influence competitiveness. But as we have seen, a policy that goes too far in the other direction - defining markets based on actual flows - also results in a biased market definition, because it reflects too many factors other than competitiveness.

For these reasons, recent industrial-organization studies have tended to focus on how consumers choose among alternative firms, and not on "market structure" based on arbitrary geographic boundaries. Ideally, consumer demand for a hospital as a function of cost and quality would be fully known, making it straightforward to determine whether a proposed merger or any other change affecting potential competitors would affect social welfare. The effects on consumer and producer surplus, and not the effects on any necessarily arbitrary "market," would provide the foundation for evaluating competitive effects. But determining hospital (or any other) demand functions is extremely difficult, for much the same reasons that endogeneity problems exist in traditional measures of market structure. If a neighboring hospital is particularly high-quality, then the effects of distance and other patient characteristics that influence choices will appear different than for a hospital that is lower-quality. Some published studies in industries other than health care have avoided these problems by imposing additional assumptions. These assumptions provide "exogenous" variations in firm quality or cost that can

competitiveness of more competitive markets, and will understate the competitiveness of less competitive markets. Such correlation is likely because increases in geographic market size, all else constant, increase measured competition, so that estimates of the impact of competition are smaller in absolute value than the actual impact of competition. 
be observed and studied to estimate demand functions. But such assumptions are particularly difficult to sustain for hospital care, in which observable exogenous differences in quality and cost are often correlated with unobserved influences that may be correlated with but not caused by differences in competitiveness.

\section{Impact of Changes in Competitiveness on Patient and Social Welfare}

Assuming that competitiveness in the areas served by a hospital could be defined appropriately, the next step is to quantify the impact of the proposed merger on the market, with an index such as the HHI. Basic microeconomic theory naturally suggests that more competitive markets -- that is, markets with lower HHIs -- should make patients and society better off, but many theoretical studies in economics have questioned this relationship in the health care sector. For this reason, knowing the specific relationships among changes in competitiveness, medical costs, and patient health outcomes is also crucial for evaluating mergers.

The theoretical studies have noted that markets for health care services in general, and markets for hospital services in particular, deviate substantially from the stylized conditions required by basic theory for competition to result in efficient outcomes. These conditions include the existence of multiple buyers and multiple sellers of a product or service who act as price takers, enjoy full or at least symmetric information, and bear the full costs of their actions at the margin. By considering conditions that plausibly deviate from these basic assumptions, models of hospital competition suggest that it may either improve or reduce social welfare.

Many models of how hospital competition may reduce social welfare focus on distorted price signals and a more general absence of price competition. Insurance and tax incentives may 
make consumers relatively insensitive to price, for example, so that hospitals in more competitive markets engage in a medical arms race (MAR) and supply socially excessive levels of medical care (Salkever 1978; Robinson and Luft 1985). ${ }^{6}$ Further, hospitals were historically reimbursed on a "cost-plus" basis, so that they too did not bear the marginal costs of intensive treatment decisions. In addition, "quality competition" may be socially excessive because of price regulation in the health care industry (see Joskow 1983 and McClellan 1994 for a discussion). Simple models of the airline industry (e.g., Douglas and Miller 1974, Panzar 1975, Schmalensee 1977), for example, showed that regulated pricing induced airlines to engage in nonprice competition, leading airline markets with greater numbers of competitors to have higher service levels. If the additional intensity of medical care resulting from competition is excessive, in terms of improvements in patient health outcomes whose value is less than the social costs of production, then competition among hospitals would be socially wasteful.

MAR models tend to be viewed as theoretically outdated, because of improved price competition among health plans. Competition among insurers may lead to more effective bargaining over prices with providers (e.g., Town and Vistnes 1997), or to patterns of care that use medical technology in a more cost-effective way (e.g, Pauly 1988). To the extent that

${ }^{6}$ The original MAR hypothesis was formulated around the idea that hospitals compete for patients through competition for their physicians, by providing a wide range of equipment and service capabilities. Greater availability of equipment may induce physicians to admit their patients to a hospital for several reasons. If physicians are uncertain about the necessity of various intensive treatments at the time the admission decision is made, then additional service capabilities may allow them to provide higher-quality care. Also, to the extent that high-tech equipment is a complement to compensated physician effort, additional equipment may allow physicians to bill for more services; to the extent that equipment is a substitute for uncompensated physician effort, additional equipment allows physician to work less for the same level of compensation. 
managed-care plans have more capacity to negotiate and influence hospital practices, and consumers pay for the marginal differences in premiums across managed-care plans, price competition has become a more prominent feature of hospital competition with the growth of managed care (Enthoven 1993). Such price competition is likely to be greatest in areas where managed-care health plans are most widespread.

Other aspects of hospital production besides the effects of insurance and managed care on price and quality competition also make it difficult to draw definitive theoretical conclusions about the consequences of competition. Informational imperfections in hospital markets may cause competition to reduce social welfare (e.g., Satterthwaite 1979, Frech 1996). In addition, if hospital markets are monopolistically competitive rather than perfectly competitive, more competition may lead to less efficient levels of care (e.g., Frech 1996). Although conventional wisdom is that monopolistic competition in hospital markets yields too many providers and excess capacity (with no hospital large enough to exhaust returns to scale), in fact monopolistic competition can lead to either socially excessive or inadequate capacity (Tirole 1988, Sec. 7.2). Further, a substantial fraction of hospitals are nonprofit institutions, which may have different objectives and behave differently than their for-profit counterparts (e.g., Hansmann 1987; Kopit and McCann 1988; Lynk 1995). Models of competition based on for-profit objectives may not accurately characterize the welfare implications of interactions in hospital markets.

Finally, identifying the effect of competition is complicated by other hospital or area factors that may be correlated with it, or that may mediate its effects. These additional factors include hospital bed capacity and competition in health insurance markets. Measuring the impact of these factors on expenditures and health outcomes is important in its own right. Substantial 
research, starting with Fuchs (1972), has suggested that high levels of bed capacity per patient lead to longer lengths of stay and higher costs; more recent research indicates that hospitals which treat relatively few cases of any particular type may deliver lower-quality care. On the other hand, high levels of capacity per patient may reduce the travel distance and time necessary to obtain treatment, which may lead to improved health outcomes.

This theoretical ambiguity suggests that empirical evidence should be used to guide antitrust enforcement. Many empirical studies have investigated the consequences of hospital competition (see Gaynor and Haas-Wilson 1997 and Dranove and White 1994 for comprehensive reviews). In summary, research based on data from prior to the mid-1980s finds that competition among hospitals leads to increases in excess capacity, costs, and prices (Joskow 1980; Robinson and Luft 1985, 1987; Noether 1988; Robinson 1988; Robinson et al. 1988; Hughes and Luft 1991). Research based on more recent data generally finds that competition among hospitals leads to reductions in excess capacity, costs, and prices (Zwanziger and Melnick 1988; Wooley 1989; Dranove, Shanley, and Simon 1992; Melnick et al. 1992; Dranove, Shanley, and White 1993; Gruber 1994), with some important exceptions that find negative effects of competition even post-1983 (Robinson and Luft 1988; Mannheim et al. 1994).

The empirical literature has two well-known limitations. First and foremost, the literature does not assess directly the social costs and social benefits of competition; as a result, it is not possible to draw any conclusions about patient welfare without strong additional assumptions. Some studies do not try to measure resource use at all. Many that do use "list" charges rather than transaction prices (e.g., Noether 1988) even though fewer and fewer patients pay undiscounted prices (Dranove, Shanley, and White 1993). Even those studies that use 
transaction prices (e.g., Melnick et al. 1992) or account for list-price/cost margins (e.g., Dranove, Shanley, and White 1993) analyze the prices for a fixed basket of services, despite the fact that the welfare losses from the absence of hospital competition are likely to arise from changes in the mix of services provided, rather than from increases in prices for a given basket of services. Other studies measure the effects of competition on the profitability of for-profit hospitals (Wooley 1989), on accounting costs per case-mix adjusted admission (Robinson and Luft 1985, 1987, 1988; Zwanziger and Melnick 1988; Mannheim et al. 1994), on employment of specialized personnel (Robinson 1988), on lengths of stay (Robinson et al. 1988), and on patterns of provision of specific hospital services (Hughes and Luft 1991; Dranove, Shanley, and Simon 1992).

We have identified only one previous economic study that sought to assess the consequences of competition for patient health outcomes. Shortell and Hughes (1988) find no statistically-significant effects of hospital competition on in-hospital mortality rates for Medicare patients in 1983-84. However, they only investigate the effect of competition on in-hospital mortality. This is an incomplete measure of health: if longer hospital stays improve patient health but provide more time for deaths to occur, better outcomes might be associated with higher in-hospital mortality. No studies have examined comprehensive or longer-term health effects.

Second, determining the empirical relationship between competitiveness and industry performance is subject to the same endogeneity problems that arise in defining markets. For example, some studies have calculated HHIs equal to the sum of squared shares of hospital beds or number of admissions in a given geographic market, matched HHIs to individual patients 
based on their hospital of admission, and then estimated the impact of the HHI on the cost of a baseline type of hospital admission or on the price of a particular treatment. This can lead to biased estimates of the impact of market structure because a patient's hospital of admission, and thus her $\mathrm{HHI}$, may depend on unobserved determinants of her health status. Suppose patients who are sicker value hospital quality more highly, and require more costly treatment. If the true effect of competition is to reduce costs and improve quality, then the fact that such sicker patients value higher-quality hospitals more will induce a negative correlation between a hospital's HHI and costs (and induce positive correlation between a hospital's HHI and patient health outcomes). Put another way, unobserved patient heterogeneity will lead to underestimation of the beneficial impact of competition on both costs and on health outcomes, and may even lead to the conclusion that competition is socially wasteful, if bias resulting from patient selection is sufficiently large.

In any event, most of these studies are now viewed as less relevant because of changes in the health care industry in the 1990 s, most notably the growth of managed care. Increased managed care penetration is generally a reflection of price and quality competition in health insurance purchasing decisions, and is associated with slower growth in medical expenditures (Baker 1996). However, few studies have examined the consequences of managed care growth for health outcomes, leaving important unresolved questions about the impact of managed care on patient welfare. Moreover, existing studies provide little insight into the mechanism through which managed care achieves its effects, and most importantly into how managed care may interact with competition in hospital markets. Can it substitute for hospital competition in limiting medical spending, or does competition among hospital enhance its effects? And do the 
consequences of managed care for health outcomes differ in areas with more or less competition among providers? Surprisingly, even though negotiations and other interactions with hospitals and other providers are the principal mechanism through which managed care is thought to influence medical practices, no studies have examined how managed care interacts with hospital competition to affect patient well-being.

Thus, although the previous literature has provided a range of insights about variation in hospital competition and the relation of competitiveness to measures of hospitals' behavior, it has not provided direct empirical evidence on how competition affects social welfare. Furthermore, because the literature has analyzed measures of market competitiveness that are not based on exogenous determinants of the demand for hospital services, and because these measures may be correlated with other determinants of costs and outcomes like hospital capacity, the resulting estimates of the effects of competition may be biased. Finally, very few studies have assessed the effects of competition in recent health care environments, in which managed care figures prominently.

As a result, neither the theoretical nor the existing empirical literature in health economics provides clear guidance for antitrust policy. Current enforcement policies are implicitly based on the assumption that competition improves social welfare, but the foundations for such policies are at best uncertain. This lack of clear guidance for assessing the impact of a merger on competitiveness, and in turn for assessing the implications of changes in competitiveness for patient well-being and social welfare, may account for some recent difficulties faced by government agencies in winning hospital merger cases. Virtually no previous empirical research has developed measures of competitiveness that do not suffer from 
the biases created by traditional approaches to market definition. No previous studies have examined effects of competition on both health care costs and patient health outcomes. Without these elements, conclusions about the effects of a merger on welfare are necessarily highly speculative.

\section{Recent Kessler-McClellan Research on Hospital Competition}

\section{Methods}

Our recent research seeks to address these weaknesses in the foundations of hospital antitrust policy. Our initial research has studied the effects of hospital competition for all nonrural elderly Medicare recipients hospitalized for a treatment of a new heart attack and other types of coronary heart disease in 1985-1994. ${ }^{7}$ We focus on particular illnesses to allow us to

${ }^{7}$ Competition among hospitals may seem relevant only to privately-insured patients and government patients in managed-care plans, and not most Medicare patients. "Traditional" Medicare compensates hospitals on the basis of a diagnosis-related group (DRG) payment system. Because the DRG system appears to compensate hospitals on a fixed-price basis per admission for treatment, and Medicare does not bargain with individual hospitals, Medicare patients might appear to be less affected by competition due to the "high-powered" payment incentives to minimize cost. However, competition may affect Medicare patients both through "direct" and "spillover" effects.

Competition may have direct effects on Medicare patients because the intensity of treatment of all health problems may vary enormously, and because the DRG system actually contains important elements of cost sharing (McClellan 1994, 1997). For example, many DRGs are related to intensive treatments such as cardiac catheterization and bypass surgery, rather than to diagnoses such as heart attack. Thus, for most health problems, hospitals that provide more intensive treatment and incur higher costs can receive considerable additional payments. To the extent that Medicare provides hospitals with low-powered, cost-plus incentives, it may support MAR-type quality competition and thereby create social losses due to the provision of excessive care.

Even if reimbursement rules and other factors limit the direct impact of competition on publicly-insured patients in programs like Medicare, competition for privately-insured patients may have important spillover effects. To the extent that competition improves the efficiency of treatment of privately-insured patients and physicians do not develop distinctive practice patterns 
study effects of competition on important health outcomes as well as on treatment and resource use; relevant outcomes differ by disease. Treatment of heart disease is the largest single component of hospital production, accounting for around one-sixth of hospital expenditures, so it is likely to provide the best indicator of the effects of competition. As we describe below, similar methods can be applied to other common illnesses and patient populations.

We avoid the endogeneity and measurement problems in defining markets and measuring variations in competitiveness by developing models of how patients choose hospitals based on relatively exogenous characteristics of hospitals and patients. We consider how these variations in competitiveness resulting from the exögenous determinants of hospital choice interact with managed care in an area to influence medical treatment decisions, health care costs, and health care outcomes. Because we observe information on hospital competition and HMOs over a long time horizon, we estimate the impact of changes in area competitiveness on changes in hospital expenditures, readmission rates for subsequent cardiac illness, and on mortality rates, holding constant fixed effects for zip code areas. These additional features of our model allow us to control for all time-invariant heterogeneity across small geographic areas, hospitals, and patient populations.

Our first step is to analyze how patients choose hospitals, as a function of relatively

for the private and public patients they treat, Medicare patients will also benefit (Baker 1996). For example, a hospital's decision not to adopt a low-value technology benefits all patients, even if that choice primarily resulted from pressure by private managed-care insurers. Similarly, increased provision of information by providers for private purchasers may have external benefits for all patients. Conversely, spillovers might harm Medicare patients. For example, to the extent that hospitals do develop separate practice patterns for Medicare and privately-insured patients, hospitals may have a greater incentive to provide intensive treatments for Medicare beneficiaries, to recover the fixed costs of equipment that private insurers will not defray. 
exogenous (from the standpoint of individual patient decisions) characteristics of patients and hospitals. These hospital characteristics include hospital size category (e.g., less than 100 beds), teaching status, and ownership. The patient characteristics include demographic factors (age, gender, race), and distances from each patient's residence to each area hospital. All surrounding hospitals are included in our multivariate choice model, allowing us to estimate predicted probabilities of admission for each patient to each nearby hospital in the United States. These predicted probabilities allow us to construct measures of hospital market competitiveness for all heart attack patients in the United States that depend only on exogenous patient and hospital characteristics, and so are not subject to the sources of bias that we have just reviewed.

We construct a competitiveness index for each U.S. zip code using the following formula:

$$
H H I_{k}^{*}=\sum_{j=1}^{J} \alpha_{j k} \cdot\left[\sum_{k=1}^{K} \beta_{k j} \cdot\left(\sum_{j=1}^{J} \alpha_{j k}^{2}\right)\right]
$$

where $\mathrm{HHI}_{\mathrm{k}}^{*}$ is the index in zip code $\mathrm{k}$, and the $\alpha$ and $\beta$ terms refer to expected (not actual) shares of flows of patients between particular zip codes and hospitals. The expected flows are predicted from our model of hospital choices, which, in turn, are a function only of observable exogenous patient and hospital characteristics. Specifically, $\mathrm{j}$ indexes all hospitals and $\mathrm{k}$ indexes all zip codes. $\alpha_{\mathrm{jk}}$ is the expected share of patients from zip code $\mathrm{k}$ who choose hospital j. The $\alpha_{\mathrm{jk}}$ 's represent the area (zip code) perspective on patient flows, and sum to 1 across all hospitals $\mathrm{j}=1, \ldots, \mathrm{J}$. The $\beta_{\mathrm{kj}}$ 's represent the hospital perspective on patient flows, so that a particular $\beta_{\mathrm{jk}}$ is 
the expected patient flow to hospital $\mathrm{j}$ from zip code $\mathrm{k}$, as a share of the hospital's total expected patients. The $\beta_{\mathrm{kj}}$ 's sum to 1 over all zip codes $\mathrm{k}=1, \ldots, \mathrm{K}$ for each hospital $\mathrm{j}$. In a more technical paper (Kessler and McClellan 1998), we describe our competition indices in more detail.

The index of competitiveness is related to the traditional Herfindahl-Hirschman Index, but differs in important ways to more accurately reflect how hospitals compete and to avoid the biases described in the previous section. We illustrate these differences by describing each term in the index. The last term in brackets $\left(\sum \alpha_{\mathrm{jk}}{ }^{2}\right)$ is simply the expected traditional HHI for zip code k. If there were only one very large hospital nearby zip $\mathrm{k}$, then the HHI would be close to 1 ; if there were many nearby hospitals, then the HHI would be lower. The middle term $\left(\sum \beta_{\mathrm{kj}} \sum \alpha_{\mathrm{jk}}{ }^{2}\right)$ reflects the fact that a particular hospital $\mathrm{j}$ is unlikely to be able to tailor its treatment quality and cost based on a patient's particular location of residence. In principle, a hospital could increase its economic rents by price- or quality-discriminating among the patients it serves based on whether patients live in areas with few or many hospital choices. But it seems very unlikely that a hospital could effectively implement such discrimination in practice. Instead, it is much more likely that each hospital makes decisions about pricing and quality based on the collective demand function it faces, which depends on the competitiveness of all the zip codes it serves. Because zip codes that are a larger part of a hospital's expected market figure more prominently in its decisions, the appropriate measure of competitiveness facing a particular hospital is a weighted sum of the competitiveness measures of all of the zip codes it serves, with weights based on the expected shares of the zip code in the hospital's total expected patient flow. Hospital-level measures are appropriate for assessing the competitiveness facing particular hospitals. However, hospital-level performance comparisons may be biased because 
patients may choose hospitals based on their health status and preferences, and many aspects of particular cases are difficult to measure. As we have described above, if greater competition leads to higher quality of care, hospitals in more competitive areas may attract more severely ill patients. ${ }^{8}$ For this reason, we analyze competition from the perspective of zip codes of patient residence, since patients are far less likely to move across zip codes because of variations in hospital quality than they are to choose hospitals because of variations in hospital quality. ${ }^{9}$ Our competition index $\mathrm{HHI}_{\mathrm{k}}{ }^{\circ}$ is simply a weighted average of the expected competitiveness for all hospitals that are likely to treat patients from the zip code, with weights proportional to the expected patient flows from the zip to each hospital. In other words, the index is the weighted average of the competition indices for hospitals expected to treat patients in a given geographic area of residence, weighted by the hospital's expected share of that area's patients. This competition index appropriately focuses attention not on the patients actually treated by a particular hospital, but on the welfare of all patients in the area served by the hospital.

Our indices avoid the major problems facing measures of competition used in previous studies and antitrust cases. They avoid biases arising from geographic market definitions that depend on actual flows of patients. They avoid the substantial measurement error that stems

${ }^{8}$ Alternatively, wealthier or more highly-educated patients may seek out such hospitals, so that the hospitals have a healthier-than-average case mix, and competition would appear to have a greater impact on outcomes than it truly does. The main point is that the hospital-based measures of competition will be biased if quality differences have different effects on the choices of more or less severely-ill patients.

${ }^{9}$ Patients in higher-income zip codes may have intrinsically better survival capabilities. However, in a detailed analysis of medical chart review data, McClellan and Noguchi (1998) found no substantial correlations between disease severity and distances to alternative hospital types. We also include "fixed effects" for zip codes in all of our models to remove any persistent differences in health at the zip code level. 
from the use of fixed-radius or any other arbitrary geographic boundaries to define markets. And, because they measure the competitiveness of patients' areas of residence rather than the competitiveness of the markets facing their hospitals of admission, they avoid bias due to the correlation between patients' hospital choices and unobserved determinants of their health status.

Finally, in contrast to virtually all previous studies, we assess the impact of competition on both expenditures and several measures of important dimensions of patient health. This attention to both health and economic outcomes allows us to assess the welfare consequences of competition-induced differences in medical practice. These results provide a foundation for determining the "cost-effectiveness" of hospital competition. If competition among hospitals leads to lower levels of treatment intensity, but not to higher levels of adverse health outcomes, then competition among hospitals is socially beneficial. If competition leads to higher levels of intensity, but not to lower levels of adverse outcomes, competition is socially wasteful. If variations in competition either increase or decrease both costs and health, then our results still provide quantitative guidance for policies. For example, if competition-induced intensity results in low expenditures per year of life saved relative to generally accepted costs per year of life saved of other medical treatments, then competition provides incentives for efficient care; but if competition-induced intensity results in high expenditures per year of life saved, then competition provides incentives for socially excessive care. Because the precision with which we measure the consequences of hospital competition is critical, we include all U.S. elderly patients with heart diseases in 1985, 1988, 1991, and 1994 in our analysis. 


\section{Main Findings}

We find that, before 1991, competition led to higher costs and lower rates of adverse health outcomes for elderly Americans with heart disease; but after 1990, competition led both to substantially lower costs and substantially lower rates of adverse outcomes. Thus, after 1990, hospital competition unambiguously improves both patient well-being and overall social welfare. Increasing $\mathrm{HMO}$ enrollment over the sample period partially explains the dramatic change in the impact of hospital competition; hospital competition is unambiguously welfare improving throughout the sample period in geographic areas with above-median HMO enrollment rates. Furthermore, point estimates of the magnitude of the welfare benefits of competition are uniformly larger for patients from states with high HMO enrollment as of their admission date, as compared to patients from states with relatively low $\mathrm{HMO}$ enrollment. However, although HMOs have socially beneficial spillover effects throughout the sample period, the incremental social benefits attributable to HMO spillovers and hospital-competition/HMO-spillover interactions have been decreasing in magnitude over time. This finding may be due to the fact that cost-control efforts implemented by HMOs in the 1980s had, with the widespread adoption of HMOs by the 1990s, diffused to areas with relatively low HMO enrollment.

The socially beneficial impact of post- 1990 competition is nonlinear: the effect of an interquartile change in competitiveness on expenditures and outcomes is much greater for areas moving to or from the most and least competitive quartiles. Mergers that result in changes in $\mathrm{HHI}_{\mathrm{k}}{ }^{*}$ within and between the second and third quartiles of the competitiveness distribution do not have statistically or economically significant welfare implications for elderly heart disease patients. However, mergers that cause nearby areas to move into the least competitive $\mathrm{HHI}_{\mathbf{k}}{ }^{*}$ 
quartile (e.g., the highest, or first quartile), or out of the most competitive $\mathrm{HHI}_{\mathrm{k}}{ }^{*}$ quartile (e.g., the lowest, or fourth quartile), significantly reduce welfare for area residents with heart disease. Our finding that competition improves welfare post-1990 is not affected by controlling for other factors that may affect hospital market structure, such as hospital bed capacity utilization and legal reforms affecting medical practice (e.g., Kessler and McClellan 1996, 1997).

For example, in our principal model for the 1990 s, we found that reductions in competitiveness from the most to the least competitive $\mathrm{HH}_{\mathrm{k}}{ }^{*}$ quartile resulted in increased oneyear heart-attack mortality for elderly patients of approximately 1.9 percentage points (on a base of one-year heart-attack mortality of 33 percent in 1994, 5.8 percent); at the same time, such a change in market structure led to approximately 6.5 percent higher hospital expenditures for this population. Point estimates of the effects of competition on expenditures were substantially larger in areas with high HMO penetration than in areas with low penetration, but the estimated effects of competition on both mortality and other outcomes related to quality of life were similar.

\section{Implications for Antitrust Policy Toward Hospital Mergers}

Table 1 illustrates how our methods can be used to assess the welfare implications of specific hospital mergers, using as examples two hospital mergers that faced FTC scrutiny during 1994-95 (Leibenluft et al. 1997). Based on patient preferences in 1994, Table 1 answers the key question asked by the Merger Guidelines: how would hospital market competitiveness $\mathrm{HHI}_{\mathrm{k}}{ }^{*}$ change in response to the two mergers, for the eight zip codes $\mathrm{k}$ nearest to each of the merging hospitals? In particular, would either of the two hospital mergers we examine result in a change in competitiveness for one or more zip-code areas into the highest quartile, or out of the lowest 
quartile?

The top panel of the Table assesses the impact of the proposed merger between Mercy and Port Huron Hospitals, the only two general acute-care hospitals in Port Huron, Michigan (FTC vs. Local Health System, Inc., C-3618 (consent order), 61 Fed. Reg. 31,119 (June 19, 1996); No. 94 CV 74798 (E.D. Mich.) (Preliminary injunction suit filed November 30, 1994)). According to Table 1, this merger would have altered the structure of hospital markets in the surrounding area in a way that reduced patient and social welfare. Patients from every one of the surrounding eight zip codes would have experienced an increase in $\mathrm{HHI}_{\mathrm{k}}{ }^{*}$ from the second to the least-competitive quartile. For Medicare patients with heart disease, this increase in concentration would have translated into both higher expenditures and increased rates of adverse health outcomes.

The bottom panel of the table assesses the impact of the proposed merger between Freeman and Oak Hill Hospitals in Joplin, Missouri (FTC vs. Freeman Hospital, FTC Docket No. 9273; 1995-1 Trade Cas. 71,037 (W.D. Mo.); aff d 69 F.3d 260 ( $8^{\text {th }}$ Cir. 1995)). Although the merger would have increased the concentration in seven of the eight zip codes nearest to the hospitals, that increase in concentration from the third to the second quartile of the competitiveness distribution does not have statistically or economically significant welfare implications for elderly AMI patients.

Our completed studies have examined the welfare implications in one service market only, the market for heart disease care in the elderly. Our findings do not preclude the possibility that the merger would have adversely affected competition and reduced social welfare in other. markets. We also do not account for other potential benefits of the mergers, such as their impact 
on nonelderly patients and those with other illnesses. Less-acute conditions may provide greater opportunities for patients to choose among hospitals, in turn leading to greater competitiveness than for relatively acute illnesses. On the other hand, chronic conditions also provide hospitals with more opportunities to seek out profitable patients, both through choices of service offerings and through the choice of health plans with which the hospitals contract. Similarly, it is possible that privately-insured patients would be affected differently by competition than Medicareinsured patients. We leave such issues to future work, using the techniques that we have developed and applied here.

Our methods and findings do not imply that market-specific factors other than the relatively "exogenous" ones we have considered should be omitted from merger analysis. Rather, our goal is to articulate a practical analytical framework that, consistent with the Merger Guidelines, predicts accurately whether specific proposed mergers lessen competition and harm patient and social welfare. Our approach uses nationwide microdata to describe how particular types of patients choose hospitals for care, and then to determine the relationship between changes in local-area competitiveness, medical treatment intensity, and patient health outcomes over time. Our approach permits merger analyses to be driven by evidence on the welfare consequences of changes in competitiveness from areas with similar hospital choice and population characteristics, rather than potentially biased measures of market structure. 
Table I: Predicted Impact on Quartiles of $\mathrm{HHI}_{\mathbf{k}}{ }^{*}$ of Areas Surrounding Proposed Hospital Mergers That Were Subjected to FTC Action

Merger Between...

\begin{tabular}{llllll}
\hline \multicolumn{2}{l}{ Mercy Hospital, Port Huron, MI 48061 } & \multicolumn{3}{l}{ Port Huron Hospital, Port Huron, MI 48061 } \\
\hline $\begin{array}{l}\text { zip code of } \\
\text { surrounding } \\
\text { area }\end{array}$ & $\begin{array}{l}\text { HHI quartile } \\
\text { before merger }\end{array}$ & $\begin{array}{l}\text { predicted HHI } \\
\text { quartile after } \\
\text { merger }\end{array}$ & $\begin{array}{l}\text { zip code of } \\
\text { surrounding } \\
\text { area }\end{array}$ & $\begin{array}{l}\text { HHI quartile } \\
\text { before merger }\end{array}$ & $\begin{array}{l}\text { predicted HHI } \\
\text { quartile after } \\
\text { merger }\end{array}$ \\
\hline 48060 & 2 & 1 & 48060 & 2 & 1 \\
48049 & 2 & 1 & 48049 & 2 & 1 \\
48027 & 2 & 1 & 48027 & 2 & 1 \\
48040 & 2 & 1 & 48040 & 2 & 1 \\
48074 & 2 & 1 & 48074 & 2 & 1 \\
48032 & 2 & 1 & 48032 & 2 & 1 \\
48006 & 2 & 1 & 48006 & 2 & 1 \\
48022 & 2 & 1 & 48022 & 2 & 1 \\
\hline
\end{tabular}

Merger Between...

\begin{tabular}{llllll}
\hline \multicolumn{2}{l}{ Freeman Hospital, Joplin, MO 64804 } & \multicolumn{4}{l}{ Oak Hill Hospital, Joplin, MO 64804 } \\
\hline $\begin{array}{l}\text { zip code of } \\
\text { surrounding } \\
\text { area }\end{array}$ & $\begin{array}{l}\text { HHI quartile } \\
\text { before merger }\end{array}$ & $\begin{array}{l}\text { predicted HHI } \\
\text { quartile after } \\
\text { merger }\end{array}$ & $\begin{array}{l}\text { zip code of } \\
\text { surrounding } \\
\text { area }\end{array}$ & $\begin{array}{l}\text { HHI quartile } \\
\text { before merger }\end{array}$ & $\begin{array}{l}\text { predicted HHI } \\
\text { quartile after } \\
\text { merger }\end{array}$ \\
\hline 64804 & 3 & 2 & 64804 & 3 & 2 \\
64864 & 3 & 2 & 64864 & 3 & 2 \\
64801 & 3 & 2 & 64801 & 3 & 2 \\
64870 & 3 & 2 & 64870 & 3 & 2 \\
64835 & 3 & 2 & 64835 & 3 & 2 \\
64865 & 3 & 2 & 64865 & 3 & 2 \\
64850 & 3 & 3 & 64850 & 3 & 3 \\
64840 & 3 & 2 & 64840 & 3 & 2 \\
\hline
\end{tabular}

Notes: zip codes are listed in order of increasing distance from the merging hospital. 


\section{$\underline{\text { References }}$}

Baker, Laurence C., 1996, “Can Managed Care Control Health Care Costs?” draft.

Douglas, G.W. and J. C. Miller, 1974, "Quality Competition, Industry Equilibrium, and Efficiency in the Price-Constrained Airline Market," American Economic Review 64: $657-69$.

Dranove, D. et al., 1992, "Is Hospital Competition Wasteful?" RAND Journal of Economics 23: $247-62$.

Dranove, D. and M. Satterthwaite, 1992, "Monopolistic Competition When Price and Quality Are Not Perfectly Observable," RAND Journal of Economics 23: 518-34.

Dranove, D., M.. Shanley, and C. Simon, 1992, "Is Hospital Competition Wasteful?" RAND Journal of Economics 23: 247-262.

Dranove, D., M. Shanley, and W. White, 1993, "Price and Concentration in Local Hospital Markets: The Switch from Patient-Driven to Payer-Driven Competition," Journal of Law and Economics 36: 179-204.

Dranove, D. and W.D. White, 1994, "Recent Theory and Evidence on Competition in Hospital Markets," Journal of Economics and Management Strategy 3: 169-209.

Elzinga, K. and T. Hogarty, 1978, "The Problem of Geographic Market Delineation Revisited," Antitrust Bulletin 23: 1-18.

Enthoven, Alain E., 1993, "The History and Principles of Managed Competition,"Health Affairs Supplement: $24-48$.

Feldstein, Martin S., 1971, "Hospital Price Inflation: A Study of Nonprofit Price Dynamics," American Economic Review 61: 853-72.

Frech, H.E. III, 1996, Competition and Monopoly in Health Care (Washington, DC: AEI Press).

Fuchs, Victor R., 1986, The Health Economy (Cambridge, MA: Harvard University Press).

Garnick, D. et al., 1987, “Appropriate Measures of Hospital Market Areas," Health Services Research 22: 69-89.

Gaynor, Martin and Deborah Haas-Wilson, 1997, "Change, Consolidation, and Competition in Health Care Markets," draft. 
Gaynor, Martin and William Vogt, 1998, "Antitrust," in Culyer, Anthony and Joseph Newhouse, eds., Handbook of Health Economics, Amsterdam: North-Holland.

Gruber, J., 1994, "The Effect of Price Shopping in Medical Markets: Hospital Responses to PPOs in California," Journal of Health Economics 38: 183-212.

Held, Philip J. and Mark V. Pauly, 1983, "Competition and Efficiency in the End Stage Renal Disease Program," Journal of Health Economics 2: 95-118.

Hughes, Robert G. and H. Luft, 1991, "Service Patterns in Local Hospital Markets: Complementarity or Medical Arms Race?" Health Services Management Research 4: 131-9.

Joskow, Paul L., 1980, "The Effects of Competition and Regulation on Hospital Bed Supply and the Reservation Quality of the Hospital," Bell Journal of Economics 11: 421-47.

Joskow, Paul L., 1983, "Editorial: Reimbursement Policy, Cost Containment, and Non-Price Competition," Journal of Health Economics 2: 167-74.

Kessler, D.P. and M.B. McClellan, 1996, "Do Doctors Practice Defensive Medicine," Quarterly Journal of Economics 111:353-390.

Kessler, D.P. and M.B. McClellan, 1997, "How Liability Law Affects Medical Productivity," draft.

Kessler, Daniel P. and Mark B. McClellan, 1998, "Is Hospital Competition Socially Wasteful?" draft.

Kopit, W. and R. McCann, 1988, "Towards a Definitive Antitrust Standard for Nonprofit Hospital Mergers," Journal of Health Politics, Policy, and Law 13: 635-662.

Leibenluft, Robert F. et al., 1/24/97, "FTC Antitrust Actions in Health Care Services" (Washington, DC: Federal Trade Commission).

Luft, H., et al., 1990, "Does Quality Influence Choice of Hospital?" Journal of the American Medical Association 263: 2899-2906.

Lynk, William J., 1995, "Nonprofit Hospital Mergers and the Exercise of Market Power," Journal of Law and Economics 30: 437-61.

Mannheim L. M. et al., 1994, "Local Hospital Competition in Large Metropolitan Areas," Journal of Economics and Management Strategy 3: 143-67. 
McClellan, Mark, 1994, "Does More Intensive Treatment of Acute Myocardial Infarction in the Elderly Reduce Mortality?" Journal of the American Medical Association 272: 859-866.

McClellan, Mark, 1997, "Hospital Reimbursement Incentives: An Empirical Approach," Journal of Economics and Management Strategy.

Melnick, G. et al., 1992, "The Effects of Market Structure and Bargaining Position on Hospital Prices," Journal of Health Economics 11: 217-234.

Noether, M., 1988, "Competition Among Hospitals," Journal of Health Economics 7: 259-284.

Panzar, J.C., 1979, "Equilibrium and Welfare in Unregulated Airline Markets," American Economic Review 69: 92-5.

Pauly, Mark V., 1988, "A Primer on Competition in Health Care Markets," in H.E. Frech, ed., Health Care in America: The Political Economy of Hospitals and Health Insurance (San Francisco, CA: Pacific Research Institute for Public Policy).

Phibbs, C. S. and J. Robinson, 1993, "A Variable Radius Measure of Local Hospital Market Structure," Health Services Research 28: 313-324.

Robinson, J., 1988, "Hospital Quality Competition and the Economics of Imperfect Information," Milbank Memorial Quarterly 66: 465-81.

Robinson, J. and H. Luft, 1985, "The Impact of Hospital Market Structure on Patient Volume, Average Length of Stay, and the Cost of Care," Journal of Health Economics 4: 333-56.

Robinson, J. and H. Luft, 1987, "Competition and the Cost of Hospital Care, 1972 to 1982," Journal of the American Medical Association 257: 3241-5.

Robinson, J. and H. Luft, 1988, "Competition, Regulation, and Hospital Costs, 1982 to 1986," Journal of the American Medical Association 260: 2676-2681.

Robinson et al., 1988, "Hospital Competition and Surgical Length of Stay," Journal of the American Medical Association 259: 696-700.

Salkever, David S., 1978, "Competition Among Hospitals," in Warren Greenberg, ed., Competition in the Health Care Sector: Past, Present, and Future, (Germantown, MD: Aspen Press).

Satterthwaite, Mark A., 1979, "Consumer Information, Equilibrium Industry Price, and the Number of Sellers," Bell Journal of Economics 10: 472-82. 
Scheffman, D. and P. Spiller, 1987, "Geographic Market Definition Under the U.S. Department of Justice Merger Guidelines," Journal of Law and Economics 30: 123-147.

Schamalensee, Richard, 1977, "Comparative Static Properties of Regulated Airline Oligopolies," Bell Journal of Economics 8: 565-76.

Shortell, Steven and E. Hughes, 1988, "The Effects of Regulation, Competition, and Ownership on Mortality Rates Among Hospital Inpatients," New England Journal of Medicine 318: 1100-1107.

Tirole, Jean, 1988, The Theory of Industrial Organization (Cambridge, MA: MIT Press).

Town, Robert and Gregory Vistnes, 1997, "Hospital Competition in HMO Networks: An Empirical Analysis of Pricing Behavior," draft.

U.S. Department of Justice, 1992, Department of Justice/FTC Merger Guidelines.

Vistnes, Gregory, 1995, "Hospital Mergers and Antitrust Enforcement," Journal of Health Politics, Policy and Law 20: 175-190.

Werden, Gregory J., 1989, "The Limited Relevance of Patient Migration Data," Journal of Health Economics 8: 363-76.

Wooley, J.M. and H.E. Frech III, 1988, "How Hospitals Compete: A Review of the Literature," University of Florida Journal of Law and Public Policy 2: 57-99.

Wooley, J.M., 1989, "The Competitive Effects of Horizontal Mergers in the Hospital Industry," Journal of Health Economics 8: 271-91.

Zwanziger, J. and G. Melnick, 1988, "The Effects of Hospital Competition and the Medicare PPS Program on Hospital Cost Behavior in California," Journal of Health Economics 8: 457-464. 